\title{
PENGARUH PENAMBAHAN MADU DALAM PAKAN INDUK JANTAN LOBSTER AIR TAWAR RED CLAW (Cherax quadricarinatus) TERHADAP RASIO JENIS KELAMIN LARVA
}

\section{THE EFFECT OF SUPLEMENTATION OF HONEY IN FEED OF MALE MAINS FRESH WATER CRAY FISH RED CLAW (Cherax Quadricarinatus) TO LARVA SEX RATIO}

\author{
A.Taufiq Mukti, A.Shofy Mubarak dan Adde Ermawan \\ Fakultas Perikanan dan Kelautan Universitas Airlangga \\ Kampus C Mulyorejo - Surabaya 60115 Telp. 031-5911451
}

\begin{abstract}
The aim of this research was to know the effect of honey supplementation in feed of male main freshwater cray fish red claw to larva sex ratio and the level of survival of freshwater cray fish and to get the best doses of honey to give highest male sex ratio.

This research was done at Laboratory of Fishery Education, Fishery and Marines Faculty, Airlangga University in October 2007 until March 2008.

Methods of this research was experimental and used completely randomized designed with 7 treatments. Giving of honey with differences doses were A ( $0 \mathrm{ml} / \mathrm{kg})$ control, B $(50 \mathrm{ml} / \mathrm{kg}), \mathrm{C}(100 \mathrm{ml}$ $/ \mathrm{kg}$ ), D ( $150 \mathrm{ml} / \mathrm{kg}$ ), E ( $200 \mathrm{ml} / \mathrm{kg}), \mathrm{F}(250 \mathrm{ml} / \mathrm{kg}$ ) and G ( $300 \mathrm{ml} / \mathrm{kg}$ ) which each treatment got three times replicated. Data processed by Analysis of Variance (ANOVA).

The result of this research showed that supplementation of honey in feed male main freshwater cray fish red claw not significantly different to larva sex ratio and survival rate of freshwater cray fish. Otherwise, result of the supplementation of honey in feed of male main freshwater cray fish showed the increasingly male sex ratio of freshwater cray fish red claw larvae.
\end{abstract}

Key words : freshwater crayfish red claw, honey, water quality

\section{Pendahuluan}

Lobster air tawar merupakan komoditi perikanan hias akuarium dan konsumsi. Lobster air tawar adalah komoditas perikanan konsumsi yang sangat menjanjikan sebagai pengganti lobster air laut. Beberapa keunggulan lobster air tawar yaitu memiliki kandungan lemak, kolesterol dan garam yang rendah dibandingkan dengan lobster air laut serta dagingnya yang lunak dan mengandung protein yang cukup tinggi (Sukmajaya dan Suharjo, 2003).

Pandian dan Sheela (1995) dalam Syaifuddin (2004) menyatakan bahwa proses pemberian hormon steroid sintetik pada metode pembalikan jenis kelamin dapat menimbulkan stres, sehingga tingkat kelulushidupan benih, baik jantan maupun betina menjadi rendah. Dosis yang terlalu rendah menyebabkan proses pembalikan jenis kelamin berlangsung kurang sempurna dan sebaliknya jika terlalu tinggi ada kecenderungan lobster air tawar menjadi steril atau terjadi penyimpangan jenis kelamin, yaitu lobster air tawar yang diberi hormon androgen berubah menjadi betina. Benih lobster air tawar jantan secara massal dapat diperoleh dengan cara yang lebih aman, yaitu menambahkan madu ke dalam pakan induk lobster air tawar.
Madu mengandung berbagai mineral seperti kalium, kalsium, magnesium dan natrium yang bersifat alkali (Marhiyanto, 1999). Mineral-mineral tersebut mengakibatkan tubuh lobster air tawar menjadi alkali yang berpengaruh terhadap kelulushidupan kromosom $\mathrm{X}$ dan $\mathrm{Y}$ sesuai dengan sifat kromosom X dan Y. Kromosom Y lebih tahan lama pada keadaan basa, sedangkan kromosom $\mathrm{X}$ tidak dapat bertahan lama, sehingga pada saat spermiasi, jumlah kromosom Y yang dihasilkan induk jantan lebih banyak dari pada kromosom X (Toelihere, 1979 dalam Irawan, 2000). Penambahan madu pada pakan induk lobster air tawar red claw diharapkan dapat menghasilkan benih monoseks jantan secara alami dengan kelulushidupan yang tinggi, mudah diaplikasikan, lebih ekonomis dan efektif

Tujuan penelitian ini adalah untuk mengetahui pengaruh penambahan madu dengan dosis yang berbeda dalam pakan yang diberikan pada induk jantan lobster air tawar red claw terhadap rasio jenis kelamin larvanya dan mendapatkan dosis madu terbaik yang dibutuhkan untuk meningkatkan persentase kelamin jantan pada larva lobster air tawar red claw serta untuk mengetahui pengaruh penambahan madu dengan dosis yang berbeda 
dalam pakan yang diberikan pada induk jantan lobster air tawar red claw terhadap tingkat kelulushidupan larva.

Penelitian ini diharapkan dapat memberikan informasi mengenai pemberian dosis madu terbaik yang dapat meningkatkan rasio kelamin jantan pada larva lobster air tawar red claw dengan tingkat kelulushidupan larva yang tinggi.

\section{Materi dan Metode Penelitian}

Penelitian ini dilaksanakan di Laboratorium Pendidikan Perikanan Fakultas Perikanan dan Kelautan Universitas Airlangga pada bulan Oktober 2007-Maret 2008.

Alat-alat yang digunakan dalam penelitian ini adalah 21 buah akuarium, selang, batu aerasi, timbangan analitik, 1 buah gelas ukur volume $100 \mathrm{ml}$, pH meter, termometer, DO test kit dan seser. Lobster air tawar red claw yang digunakan dalam penelitian ini adalah 21 pasang induk yang telah matang kelamin diperoleh dari laboratorium Pendidikan Perikanan Universitas Airlangga. Media yang digunakan dalam penelitian ini adalah air setinggi $15 \mathrm{~cm}$ dari dasar akuarium atau kurang lebih sebanyak tiga liter. Air media penelitian berasal dari air PDAM yang dialirkan ke tandon dan diberi aerasi untuk mengurangi kandungan gas chlor dalam air media. Pakan percobaan yang digunakan dalam penelitian ini adalah pellet FF 581, sedangkan madu yang digunakan adalah madu murni yang berasal dari pohon klengkeng dikarenakan madu klengkeng terdapat banyak dipasaran.

Metode penelitian yang digunakan dalam penelitian ini adalah metode experimental. Penelitian eksperimental pada dasarnya adalah ingin menguji hubungan antara suatu sebab dengan akibat. Penelitian ini menggunakan Rancangan Acak Lengkap (RAL) dengan tujuh perlakuan dan tiga ulangan, yaitu perlakuan A dengan dosis madu $0 \mathrm{ml} / \mathrm{kg}$ pakan sebagai kontrol, perlakuan B dengan dosis madu $50 \mathrm{ml} / \mathrm{kg}$ pakan, perlakuan $\mathrm{C}$ dengan dosis madu $100 \mathrm{ml} / \mathrm{kg}$ pakan, perlakuan $\mathrm{D}$ dengan dosis madu $150 \mathrm{ml} / \mathrm{kg}$ pakan, perlakuan $\mathrm{E}$ dengan dosis madu $200 \mathrm{ml} / \mathrm{kg}$ pakan, perlakuan $\mathrm{F}$ dengan dosis madu $250 \mathrm{ml} / \mathrm{kg}$ pakan dan perlakuan $\mathrm{G}$ dengan dosis madu $300 \mathrm{ml} / \mathrm{kg}$ pakan.

Persiapan Alat - Alat Penelitian

Alat - alat yang akan digunakan dicuci dengan detergen sampai bersih, kemudian direndam klorin dan dikeringkan dibawah sinar matahari. Kemudian pada masing - masing akuarium diisi air tawar yang telah diendapkan sehari semalam setinggi $15 \mathrm{~cm}$ dari dasar akuarium, setelah itu dipasang aerasi pada masing - masing akuarium tersebut.

\section{Persiapan Pakan Perlakuan \\ Pakan yang digunakan adalah pellet} udang. Masing-masing pakan ditimbang sebanyak $200 \mathrm{~g}$ untuk tiap-tiap perlakuan yaitu sebanyak tujuh kali. Lalu disiapkan dosis madu $10 \mathrm{ml}, 20 \mathrm{ml}, 30 \mathrm{ml}, 40 \mathrm{ml}, 50 \mathrm{ml}$ dan $60 \mathrm{ml}$. Selanjutnya disiapkan aquadest untuk pengencer madu sebanyak $100 \mathrm{ml}$ pada tiap-tiap perlakuan. Campuran madu dan aquadest dicampurkan ke dalam pakan sampai rata. Setelah itu, pembuatan adonan agar-agar, yaitu dengan komposisi satu sachet jelly dan $600 \mathrm{ml}$ air. Setelah adonan agar-agar jadi, didinginkan, kemudian campuran pakan pellet, madu dan aquadest dicampurkan ke adonan agar-agar dan dibiarkan beberapa menit.

\section{Persiapan Lobster Air Tawar Red Claw Uji}

Sebanyak 21 pasang induk lobster air tawar red claw yang telah matang kelamin. Induk betina dipisahkan terlebih dahulu dari induk jantan. Induk jantan ditempatkan dalam akuarium dengan masing-masing akuarium sebanyak satu ekor induk jantan. Lobster air tawar red claw diaklimatisasi sampai memperoleh kondisi optimum.

\section{Pelaksanaan Penelitian}

Setelah diperoleh kondisi optimum, sejak dua minggu sebelum dikawinkan induk lobster air tawar betina diberi perlakuan berupa pemberian pakan yang telah ditambahkan madu setiap hari pukul 08.00 WIB dan 15.00 WIB, sedangkan induk jantan diberi pakan pellet udang saja. Pemberian pakan lebih kurang 3 persen dari berat tubuh lobster air tawar. Selanjutnya lobster air tawar dipijahkan, induk lobster air tawar betina dimasukkan dalam akuarium yang telah terdapat induk jantan dengan perbandingan satu jantan dan satu betina.

Setelah beberapa hari, lobster air tawar betina akan menetaskan larvanya. Kemudian induk lobster air tawar baik jantan maupun betina dipindahkan dari larvanya. Larva lobster air tawar dipelihara sampai dapat dilihat jenis kelaminnya lebih kurang dua bulan, kemudian dilakukan identifikasi kelamin. 
Tabel 1. Data rata-rata jumlah jantan, jumlah betina, jumlah larva total, jumlah larva mati, rata-rata persentase jenis kelamin jantan dan betina serta persentase kelulushidupan lobster air tawar red claw tiap perlakuan pemberian dosis madu pada pakan induk betina lobster air tawar red claw

\begin{tabular}{|l|c|c|c|c|c|c|c|}
\hline \multirow{2}{*}{\multicolumn{1}{c|}{ Parameter }} & \multicolumn{7}{|c|}{ Perlakuan Dosis Madu (ml/kg pakan) } \\
\cline { 2 - 8 } & $\mathrm{A}$ & $\mathrm{B}$ & $\mathrm{C}$ & $\mathrm{D}$ & $\mathrm{E}$ & $\mathrm{F}$ & $\mathrm{G}$ \\
\hline Jumlah jantan (ekor) & 50 & 52 & 49 & 55 & 55 & 64 & 66 \\
Jumlah betina (ekor) & 50 & 46 & 58 & 48 & 47 & 56 & 39 \\
Jumlah larva total (ekor) & 106 & 105 & 110 & 107 & 107 & 123 & 109 \\
Jumlah larva mati (ekor) & 6 & 7 & 3 & 4 & 5 & 3 & 4 \\
Persentase jantan (\%) & 50.52 & 52.76 & 50.38 & 52.74 & 53.61 & 53.12 & 60.35 \\
Persentase betina (\%) & 49.48 & 47.24 & 49.62 & 47.26 & 46.39 & 46.88 & 39.65 \\
Kelulushidupan (\%) & 94.15 & 93.87 & 96.97 & 96.34 & 95.71 & 97.55 & 96.97 \\
\hline
\end{tabular}

Rasio Jenis Kelamin Larva Lobster Air Tawar Red Claw

Parameter uji utama pada penelitian ini adalah persentase rasio jenis kelamin lobster air tawar red claw yang dilakukan dengan identifikasi morfologi setiap akuarium pada akhir penelitian, yaitu pada saat larva berumur dua bulan. Zairin (2002) menyatakan, rasio jenis kelamin dapat dihitung dengan rumus :

Persentase jantan $=$

Jumlah individu jantan

$\overline{\text { Jumlah individu total }} \times 100(\%)$

Tingkat Kelulushidupan

Zonneveld dkk. (1991) menyatakan bahwa tingkat kelulushidupan dapat dihitung dengan rumus :

$$
S R=\frac{\mathrm{Nt}}{\mathrm{No}} \times 100 \%
$$

Keterangan :

$S R=$ tingkat kelulushidupan benih

$\mathrm{Nt}=$ jumlah benih hidup di akhir penelitian

No $=$ jumlah benih yang hidup di awal penelitian.

Parameter penunjang, yaitu pengukuran kualitas air meliputi suhu, $\mathrm{pH}$ dan oksigen terlarut yang dilakukan setiap seminggu sekali pada pagi, siang dan sore hari yaitu pukul 08.00 WIB, 12.00 WIB dan 16.00 WIB.

Analisis data menggunakan analisis keragaman (ANOVA), sesuai dengan rancangan yang digunakan, yaitu Rancangan Acak Lengkap (RAL).

\section{Hasil dan Pembahasan}

Hasil penelitian tentang pengaruh penambahan madu dalam pakan induk jantan lobster air tawar red claw terhadap rasio kelamin larva dapat dilihat pada Tabel 1.

\section{Persentase jantan, betina dan SR}

(\%)

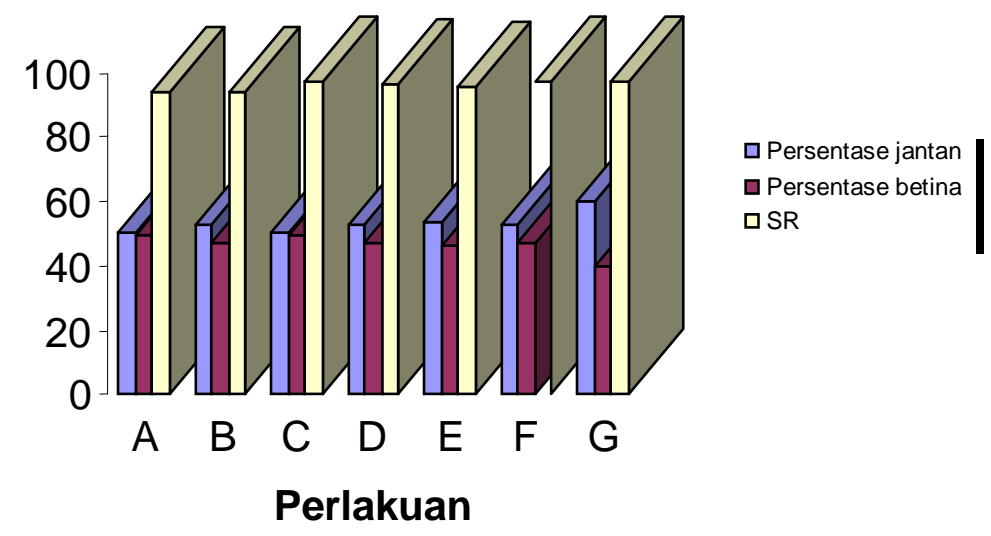

Gambar 1. Persentase jenis kelamin jantan larva lobster air tawar red claw tiap ulangan 
Rasio Jenis Kelamin Larva Lobster Air Tawar Red Claw

Tabel 1. menunjukkan bahwa persentase kelamin jantan larva lobster air tawar red claw tertinggi terdapat pada perlakuan $\mathrm{G}$, yaitu sebesar 60,35 persen, sedangkan persentase jenis kelamin jantan larva lobster air tawar red claw terendah terdapat pada perlakuan C, yaitu sebesar 46,72 persen. Persentase rasio kelamin larva setiap ulangan dapat dilihat pada Gambar 1. yang menunjukkan persentase rasio kelamin jantan larva untuk setiap ulangan pada masing-masing perlakuan.

Kualitas air pada media pemeliharaan induk yaitu, suhu air media pemeliharaan induk berkisar antara $25-28^{\circ} \mathrm{C}, \mathrm{pH} 7.0-7.8$ dan oksigen terlarut (DO) 5-7 $\mathrm{mg} / \mathrm{L}$. Pada pemeliharaan larva data kualitas air adalah suhu berkisar antara $26-29^{\circ} \mathrm{C}$, pH 7.0-7.8, dan DO 5-7 mg/L.

Sex reversal pada crustacea, khususnya pada lobster air tawar dilakukan untuk menghasilkan lobster air tawar jantan, dikarenakan lobster air tawar jantan memiliki ukuran tubuh yang relatif lebih besar dibandingkan dengan lobster air tawar betina. Sex reversal dipengaruhi oleh beberapa faktor, yaitu hormon, kualitas air, kesuburan induk, teknik dan waktu pemijahan.

Marhiyanto (1999) menyatakan bahwa dalam setiap 100 gram madu mengandung kalium sebesar 205-1676 ppm, kalsium sebesar 49-51 ppm, magnesium sebesar 19-35 ppm dan natrium sebesar $18 \mathrm{ppm}$. Mineral-mineral tersebut semuanya bersifat basa.

Analisa statistik menunjukkan tidak adanya perbedaan yang nyata antara perlakuan. Kerangka konseptual menyebutkan bahwa madu diharapkan dapat membuat saluran sperma menjadi basa sehingga sperma $\mathrm{Y}$ akan dihasilkan lebih banyak, namun kenyataannya hal tersebut tidak menyebabkan hasil yang berbeda nyata dengan kontrol. Patasik (2005) menyatakan, proses pembuahan dipengaruhi oleh beberapa faktor yaitu: kualitas semen, kesuburan betina, lingkungan serta teknik dan waktu pemijahan. Penambahan madu dalam pakan induk jantan lobster air tawar red claw, ternyata tidak menyebabkan persentase rasio jenis kelamin jantan yang berbeda nyata dengan kontrol, hal tersebut membuktikan bahwa sex reversal dengan menggunakan madu yang ditambahkan dalam pakan dengan harapan saluran sperma (vasdeferens) menjadi lebih alkalis sehingga pada akhirnya akan menghasilkan benih jantan yang dominan dari pada betina tidak terbukti, karena benih jantan yang dihasilkan tidak berbeda nyata dengan kontrol. Philips dan Hilton (1987) menyatakan bahwa untuk memperoleh individu jantan diperlukan spermatozoa $\mathrm{Y}$ yang konsentrasinya dominan, sehingga harapan anak yang dihasilkan adalah berjenis kelamin jantan lebih besar.

Pengubahan jenis kelamin atau seks reversal dapat dilakukan dengan menggunakan hormon metil testosteron, yaitu penggunaan kelenjar androgen yang dapat membalikkan arah perkembangan pembentukan indung telur, saluran sel telur dan perkembangan ciri seks skunder betina menjadi ke arah pembentukan testis, saluran sperma dan perkembangan ciri seks skunder jantan (King, 1964). Sagi dan Cohen (1990) meneliti bahwa individu jantan dewasa hasil seks reversal dengan menggunakan kelenjar androgen dapat melakukan pembuahan dan menghasilkan benih secara normal.

Kandungan mineral dalam madu yang dicampur dalam pakan sangat penting dan memberikan peranan dalam menunjang kelangsungan hidup larva dan benih lobster air tawar red claw. Mineral-mineral yang terkandung dalam madu yang masuk bersama pakan memungkinkan untuk diserap oleh embrio dan larva lobster air tawar red claw yang ada pada kandungan induk. Mineral-mineral tersebut juga diperlukan untuk meningkatkan daya tahan tubuh (Patasik, 2005)

Mortalitas pada masing-masing perlakuan pada saat dilakukan penelitian diduga disebabkan adanya kanibalisme di antara larva, kepadatan larva yang tinggi juga merupakan salah satu faktor penyebab adannya mortalitas larva. Mortalitas karena stres disebabkan karena penanganan yang kasar saat pengambilan larva yang dilakukan untuk melakukan perhitungan rasio larva.

Patasik (2005) menyatakan, penanganan yang salah dan terlalu kasar dapat mengakibatkan larva sters dan lemah, sehingga ikan mudah mati. Pengambilan dan perhitungan larva, aklimatisasi atau adaptasi larva serta pemindahan larva ke kolam pemeliharaan juga sangat mempengaruhi tingkat mortalitas larva lobster air tawar red claw (C. quadricarinatus).

Kualitas air yang meliputi oksigen terlarut, suhu dan $\mathrm{pH}$ merupakan faktor penting yang harus diperhatikan selama penelitian berlangsung, karena kualitas air dapat berpengaruh terhadap keberhasilan penlitian. Air memiliki kapasites spesifik terhadap panas, artinya perubahan suhu dapat ditahan dan terjadi relatif lambat. Suhu air mempengaruhi reasksi kimia, baik dalam media luar maupun dala tubuh ikan. Suhu makin naik maka reaksi kimia akan terjadi semakin cepat, sedangkan 
konsentrasi gas dalam air akan semakinturun, termasuk oksigen. Suhu luar atau eksternal yang berfluktuasi terlalu besar akan berpengaruh terhadap sistem metabolisme (Fujaya, 2004). Suhu pada pemeliharaan larva berkisar antara 26-29 ${ }^{\circ} \mathrm{C}$, sedangkan pada pemeliharaan induk berkisar antara $25-28^{\circ} \mathrm{C}$.

Derajat keasaman $(\mathrm{pH})$ merupakan indikasi air bersifat asam, basa atau netral. Derajat keasaman menentukan proses kimiawi dalam air (Lesmana, 2002). Derajat keasaman $(\mathrm{pH})$ rata-rata selama penelitian pada pemeliharaan larva berkisar antara 7.0 hingga 7.8. Oksigen terlarut pada pemeliharaan larva berkisar antara 5-7 mg/Lt, sedangkan pada pemeliharaan induk berkisar antara 5-7 mg/L

\section{Kesimpulan}

Hasil penelitian tentang pengaruh penambahan madu dalam pakan induk jantan lobster air tawar red claw (C. quadricarinatus) terhadap rasio jenis kelamin larva dapat diambil simpulan sebagai berikut: Hasil penambahan bahan madu dalam pakan induk jantan lobster air tawar red claw tidak menunjukkan perbedaan yang nyata terhadap rasio jenis kelamin jantan larvanya dan dosis madu sebesar $300 \mathrm{ml} / \mathrm{kg}$ dalam pakan induk jantan dapat menghasilkan benih lobster air tawar red claw jantan sebesar 60.35 persen, selanjutnya hasil penambahan bahan madu dalam pakan induk jantan lobster air tawar red claw tidak menunjukkan perbedaan yang nyata terhadap tingkat keluluhhidupan larva, semua perlakuan menunjukkan tingkat kelulushidupan benih diatas 90 persen.

Pada prinsipnya masih diperlukan adanya penelitian lebih lanjut mengenai dosis yang lebih tinggi, dikarenakan pada dosis tertinggi yaitu $300 \mathrm{ml} / \mathrm{kg}$ didapatkan benih jantan tertinggi, maka penelitian lanjutan diperlukan untuk mengetahui bagaimana pengaruh madu dengan dosis yang lebih tinggi, serta memperhatikan mengenai cara pencampuran madu dengan pakan bentuk pellet agar madu tidak cepat berkurang kadarnya dalam air.

\section{Daftar Pustaka}

Bachtiar. 2006. Mengenal Red Claw dan Habitatnya. Agromedia Pustaka. Jakarta. hal. 1-75.

Busseltonrural, C. 2006. Kebutuhan Nutrisi Lobster Air Tawar (Cherax quadricarinatus). www.specialtyfeeds.com.
Fujaya, Y. 2004. Fisiologi Hewan Air. Rineka Cipta. Jakarta. hal. 56-60.

Holthuis, L. B. 2004. Taxonomy of Cherax sp. http://147.72.68.29/crayfish . 7 November 2007. 2 pp.

Humphreys, S. 2004. Yabbie Crayfish (Cherax destructor). http://www.growfish.com. November 2007. 4 pp.

Irawan, D. 2000. Pemisahan Sel Spermatozoa Sapi Madura Kromosom Sex X dan Y Dengan Teknik Sentrifugasi Menggunakan Kolom Percoll. Skripsi. Fakultas Kedokteran Hewan. Universitas Airlangga. Surabaya. hal.7.

Iskandar. 2003. Budidaya Lobster Air Tawar. Agromedia Pustaka. Jakarta. hal.150 .

King, D. S. 1964. Fine structure of the androgenic gland of the crab, Pachygrapsus crassipes. Gen. Comp. Endocrinol, 4.hal.533-544.

Kusriningrum, R. 1990. Dasar Perencanaan Percobaan dan Rancangan Acak Lengkap. Fakultas Kedokteran Hewan Universitas Airlangga. Surabaya. hal. 143.

Marhiyanto, B. 1999. Peluang Bisnis Beternak Lebah Madu. Gitamedia. Surabaya. hal. 95.

Massers M.P. and David B.R. 1997. Australian Red Claw Crayfish. SRAC Publication No.244. hal 1-98

Mukti, A. T., W. H Satyantini dan M. Arief. 2003. Dasar-Dasar Akuakultur. Program Studi Budidaya Perairan. Fakultas Kedokteran Hewan. Universitas Airlangga. Surabaya. hal. 81-98.

Patasik, S. 2005. Pembenihan Lobster Air Tawar Lokal Papua. Penebar Swadaya. Jakarta. hal. 5-10.

Phillips, H. and T. Hilton. 1987. Ingin Anak Laki-laki atau Perempuan. Penerbit Arcan. Jakarta.hal 1- 96.

Riyanto, A. 2001. Pengaruh Pemberian Suplemen Madu pada Induk Mencit terhadap Rasio Kelamin Anaknya. Berita Biologi, 5 (4) : 439-440.

Sagi, A., and D. Cohen. 1990. Growth, maturation and progeny of sexreversed Macrobrachium rosenbergii males. World Aquacult, 21.hal.87-90.

Sahwan, M. F. 2003. Pakan Ikan dan Udang : Formulasi Pakan Buatan, Analisis 
Ekonomi. Penebar Swadaya. Jakarta. hal. 1-2.

Silalahi, G.A. 2003. Metodologi Penelitian dan Studi Kasus. Citramedia. Sidoarjo. hal. 152.

Sukmajaya dan Suharjo. 2003. Lobster Air Tawar Komoditas Perikanan Prospektif. Agromedia Pustaka. Jakarta. hal. 1-56.

Sumoprastowo, R.M dan A. Suprapto. 1980. Beternak Lebah Madu Modern. Bhratara Karya Aksara. Jakarta. hal. 95-101.

Suranto, A. 2004. Khasiat dan Manfaat Madu Herbal. Agromedia Pustaka. Jakarta. hal. hal. 70-79.

Suyatno, Sumarwoko dan R. R. Panggabean. 2006. Menjadi Jutawan Dengan Pembenihan Lobster Air Tawar. Kanisius. Yogyakarta. hal.1-56.
Syaifuddin, A.2004. Pengaruh Pemberian Suplemen Madu pada Pakan Larva Ikan Nila Gift (Oreochromis niloticus) terhadap Rasio Jenis Kelaminnya.Skripsi. Fakultas Perikanan. Universitas Brawijaya. Malang.hal.1- 69.

Winarno. 1995. Kimia Pangan dan Gizi. Gramedia. Jakarta. hal. 156-167.

Wiyanto, R. dan Hartono. 2004. Lobster Air Tawar dan Perkembangbiakannya. Gramedia. Jakarta. hal. 86.

Withnall, F.2006. Freshwater Yabby. http:www.amonline.net. 7 November 2007. 1 pp.

Zairin, Jr., 2002. Sex Reversal, Memproduksi Benih Ikan Jantan atau Betina. Penebar Swadaya. Jakarta. hal. 88.

Zonneveld, N., Huisman, E.A., Boon, J.H. 1991. Prinsip-prinsip Budidaya Ikan. Gramedia Pustaka Utama. Jakarta. hal. 31 . 